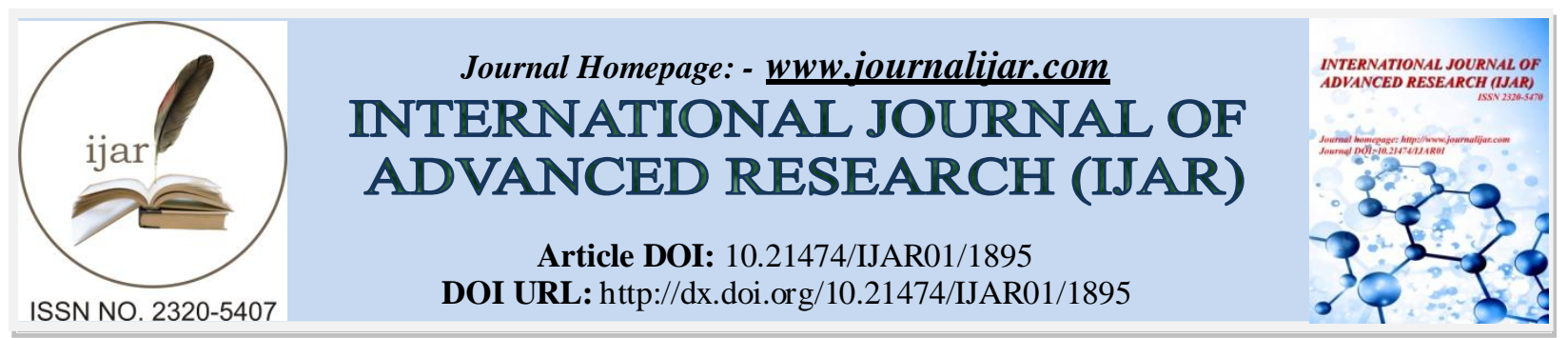

RESEARCH ARTICLE

\title{
DEPLOYING CREATIVE DESIGN BELOW-THE- LINE MEDIA TO ENHANCE BRAND VISBILITY IN SOUTH- EAST AND SOUTH-SOUTH NIGERIA
}

\author{
Dr. John Amifor frpa. \\ Nnamdi Azikiwe University, Awka.
}

\section{Manuscript Info \\ Manuscript History \\ Received: 12 August 2016 Final \\ Accepted: 22 September 2016 \\ Published: October 2016}

Key words:-

Marketing strategies. Creative mix.

Creative hotshop, and execution. Media.

\section{Abstract}

A given market determines the type of advertising strategy to be deployed in it. Nigeria as an integral part of global market, media outlet in its global nature reflects in convergence of both the traditional and new media. Media are visible contenders for the attention of consumers in both South - East and South- South geographical market space. Also, the method of message production and delivery invariably determines audience shift in patronage. Considered influential is the consumers penchant for imported multinational products from Europe, United States and Asia countries. Full service advertising agency as well as creative shops are nonexistence in the market zones. Domiciled clientele is limited to medium rather than large scale patronage in such competitive market. Integrated Marketing Communication dictates throws up the need for specialized creative shops. Marketing strategies encompassing communication mix, creative and media tailored to limited budgets are imperative. The paper locates skillful hands and well groomed graphic professionals from the local university as resource people. Sources of finance and the architecture for modest Creative shop are revealed.

Copy Right, IJAR, 2016,. All rights reserved.

\begin{abstract}
Introduction:-
Evolutionary trends in global advertising constantly remind us that, the consumer as a king uses perception as sensory inputs to decode quality of product or services in persuasive message construct. The resultant action becomes reality as messages, both product and services in media channels constantly confront us daily in whatever global market today to trigger subsequent action and patronage. Given the above espouse, and reality as well as the relationship between advertising practice, the advertisers and the public could be described as symbiotic in the South east and the South-south marketplace. There are abundant parity products with slight nuances as well as consumers for both authentic and fake brands, all competing for proportional share of the market. The variant between consumers purchasing power is pricing. Reputable global brand names including the locals saturate the market space of the South East and the South-South. Media presence is also competitive and saturated.
\end{abstract}

\section{Extent of Market:-}

Consumers in these geographical region of Nigeria are active participants in global market space both as importers, consumers as well as distributors of imported goods from overseas. Sizable manufacturing companies are located in the region. Their products include: plastic goods, automobile, pharmaceuticals, beauty products toilet soap, roofing 
sheets animal feeds, textile, poultry, and beverages among others. These companies are in competition with multinationals such as the Unilever, Cadbury, Nestle, Procter and Gamble, Nigerian Brewery Plc, but with limited budget on advertising. The multinationals located in mostly Lagos, the nation commercial nerve centre and overseas have numerous advantages over their local competitors which include: management, financial and marketing strategies, more importantly, economy of large scale production. Benefit of the multinational advantages perfectly fits into Burton (2010) rationale that "Advertising as an activity stands for the ideology of the marketplace - commercial competition, company expansion, promotion of products, pleasing customers, and maximizing profits - at any price" From the overview of practice Advertising is a paid form of persuasive communication that uses mass and interactive media to reach broad audiences in other to connect an identified sponsor with buyers (a target audience) and provide information about products (goods, services and ideas). Reasonably, 99\% of advertising agencies including their international affiliates are located in Lagos and overseas. In facts, most of the multinational products are available in Nigeria's marketplace even as their headquarters are located overseas. Decisions on the method of production of creative messages for overseas markets are mostly taken abroad also. Invariably both South east and the South South consumers are exposed to the traditional and the new media information messages - an added advantage in combined above - the - line and below - the - line.

In addition, the following research, as well as extent of the market, extensive notion of non -measurable media which include below-the-line nomenclature was explored.

„Support media are referred to by several titles among them alternative media, bellow - the - line media, non measured media, and non traditional media. These terms describe a vast variety of channels used to deliver communications and to promote products and services. Global evolutionary trends in advertising practice have developed new dimensions to the existing sites of bellow - the - line platforms. (Belch and Belch 2012)

The premises in this broad definition show that practice include other important factors that drive brand equity and are under scored by media, audience and objectives - achievable goals. While Onitsha hosts the largest market in West Africa, other centers include Aba and Port Harcourt. Perhaps in similar vein resort to Moriarty, Mitchell and Wells (2009) is desirable to elucidate five basic factors identified in various definitions, aimed at effective advertising. The nature of advertising itself embodies primary and secondary categorization of media nomenclature in an attempt to attain brand equity. The above - the - line references the newspapers, magazines, electronics and the internet campaign focus. While below - the - line media supplement the primary media campaign effort with point of sale (POS) or point of purchase (POP) effort. In between both media is the outdoor platform as functional reminder medium. To achieve creative impact meaning strategic communication aimed at certain favorable consumer response, both above-the-line and below-the-line have symbiotic relevance. But we can deploy below-theline alone for the limited budget of small scale enterprises by using the synergy of strategy, the creative idea, the creative execution and the media in message delivery as crucial factors.

The research method methodology adopted in this paper is analytical rested on Behavior- Oriented focused on actions and reactions of people as enunciated by Rubin, Rubin, Haridakis and Piele (2010). Their espouse clearly stated that "communication research includes self- reports of attitudes and behaviors via survey questionnaires, observations of other people "s behavior and experimental research". Their work sought to describe or narrate current attitudes,, opinion, thoughts, and, or perhaps reports of behavioral inclinations. Recourse to Vakratsas and Ambler (in Belch and Belch,2012) in similar manner reinforces the behavioral pattern theory, which seemingly represents the campaign efforts of the multinationals among other advertisers located in the geographical markets. Meanwhile, the authors reviewed more than 250 journal articles and books regarding the third block under Consumer between advertising and purchase hierarchy, showing the "how advertising works and affects the consumers" Their findings listed three basic intermediate effects between advertising and purchase namely: cognition as the "thinking" dimension of a person's response; affect which is the "feeling" as well as the experience which represents the feedback such as purchase and response. What ultimately drives the market under study is Cognition related to individual "thinking" as a result of the designed messages received as well as level of response. Meanwhile, Affect, represents "feeling" associated with both experience in the realm of feedback from the product purchased and used. Finally, on feeling for instance rests the behaviors of the consumer based on influence of the message construct. The theoretical framework on which this work is based is a recourse to amplification in similar vein by Belch and Belch $(2012$,a). that "individual responses to advertising are mediated or filtered by factors such as motivation and ability to process information, which can radically alter or change the individual response to advertising" From the literature espouse, content of persuasive message is as important as the message itself, the media inclusive. 
Based on the above espouse, participants to recently concluded on Brand Management workshop organized by the Advertising Practitioners Council of Nigeria ( APCON ) on the possibility of using Below - the - line strategy for effective brand visibility in both South East and South- South market zones of Nigeria were used as respondents for the study. Present among the participants were brand managers from the manufacturing sectors, company directors, academicians, practitioners, collateral material producers among others. As a matter of fact, one facilitated the program partly. The paper explores the possibilities of deploying below - the -line creative designs given low budget of the local clients in these two geographical zones to remain in competition. Choice of the participants for survey was based on the facts that, they are aware of the preferential attitude by consumers towards imported products which accommodates competitive pricing and an apparent lob- sided markets in both zones. In addition, the second factor considered was that the participants are involved in marketing strategies based on research surveys as well as design hierarchies of messages mediated in various media, most being products of Lagos and Overseas advertising agencies. The workshop, therefore, explored how practitioners at the local level could appropriate below - the - line creative materials for clients brand visibility within the South - east and the South - south market zones given their low budget status.

Shortly before the end of the workshop, (40) Questionnaires" were distributed to (40) participants of management cadre, essentially to ascertain and establish the production sources of (5) designs in the ratio of (2) foreign as seen in (Plates1.1, and 1.2),(1) local design as revealed in (Plate2), and (2) designs (Plates 3.1 and 3.2)respectively by graphic design graduates of Nnamdi Azikiwe University Awka. The result revealed that, (35) among the participants were convinced that, (4) designs originated from Lagos and overseas. Further, (5) were unsure of their sources. Meanwhile, all the (40) respondents recognized the source of fifth design as a local product designed by a collateral service provider. The process recognized $87.5 \%$ as frequency representing the 35 respondents who identified (4) designs as sourced from outside the local zone. Meanwhile, $2 \%$ represents (1) local design, and, $8.00 \%$ as those (5)who could not establish sources of the designs.

\section{Time and space:-}

Change evolves rapidly in contemporary advertising field as we continue to keep pace with its evolutionary trends. The reality at the marketplace suggests that, the relationship between advertising practice, the advertiser, and the public could be described as symbiotic. Such synergy responds to Burton $(2010, a)$ assertion earlier noted that “ advertising as an activity stands for ideology of the marketplace - commercial competition, company expansion, promotion of products, pleasing customers, maximizing profits - at any price" What makes these symbioses work is predicated by the nature of Nigeria's economy reflective of her GDP which over the years fluctuates. This fact could be discerned from Iwuala (2011) "The microeconomic picture of Nigeria had average GDP growth of 7\% with anticipated optimism expressed it could reach $7 \%$ to $8 \%$ in the medium terms" "In the 20, 20 vision, we have aspirational goals of $11 \%$ a year"

The optimism of Okonjo Iwuala, Nigeriaes finance minister and the chairman of the national economic council reflected in the quality of technocrats gathered by the president of Nigeria Dr. Goodluck Jonathan to grow Nigeria's economy. Aptly, she envisaged that growth from the year 2012 to2050 as well as the expectations that the country would be Africa's largest economy by 2025, overtaking South Africa. The new attitude aimed to grow the economy was on course before the free fall of oil prices globally from the middle of 2015. New leadership led by President Muhammadu Buhari who assumed office in May, 29, 2015 is yet to chart new economic policy. But, in spite of the current economic downturn, Nigeria's marketplace still accommodates global products from global multinationals companies from the Europe, United States and Asian countries just as the consumers still think and act in both local and global attitude.

\section{Marketing Plan- Strategy:-}

Marketing negotiates the need to facilitate exchange process and build relationship to develop needs as well as Products capable of satisfying consumers. In addition, price, channels of distribution and communication mix, including media channels are considered valuable components required to attain set objectives. Marketing strategy must be planned utilizing the four Ps as follows: Products which are readily available in the market, price which is competitive within market space, place as distribution outlet and promotion. What we refer to as below-the-line media resonate from the materials of untypical in store media usually appropriated to support the primary media, and sales promotion, word of mouth marketing, public relations, event marketing among others given marketing communication mix. 
Marketing mix which includes communication mix, media mix, and more importantly, as IMC dictates that resonates from costumer care aimed to sustain satisfaction through understanding. Facilities such as platform to deal with customer complain, enquiries, and needs as well as feedback are part of such dictates. Interactive website and hotline are also prerequisites.

\section{Integrated Marketing Communication dimension:-}

Facilitating the exchange process, developing a product that satisfies the need and wants of consumers at reasonable price has been the domain of marketing. The essence of IMC is described by Schultz (in Belch and Belch 2012) as follows: "Integrated marketing communication is a strategic business process used to plan, develop, execute and evaluate coordinated, measurable, persuasive brand communications programs over time with consumers, prospects, employers, associates and other targeted relevance and internal audiences. The goal is to negotiate both short term financial returns and build long - term and share holder value". In addition is making such products available through channels of distribution as well as providing program of promotion or advertising communication awareness including generating patronage; these are all marketing strategies identifiable in the marketing space of the South - east and South - south zones. Aptly, the four Ps, product, price, place (distribution), and promotion are integral part of marketing mix, particularly at these specific sites. None measurable media has improved noticeably. According to Smith and Taylor (2010) "There was a time when below-the line point of sales (POS) materials were considered relevant only to cosmetics, perfumery, confectionary and other impulse purchases". Today, merchandising technologies apply to a broader spectrum of markets, from consumer to industrial.

Along the line, during 1980s following media clutter and subsequent broadening perspective of marketing such as sales promotion, direct marketing, and public relation expanded rapidly; the traditional advertising agency overall control of marketing communication mix came under intense challenge. In addition, companies began to divest beyond the traditional advertising agencies. Invariably, the concept of integrated marketing communication synergy was evolved to diversify practice and to coordinate various elements of communications. The new attitude took into cognizance media fragmentation as well as clutter; therefore marketers resorted to increase spending much budget on more targeted media that reach specific audience towards micromarketing - it has also proved that new generation of consumers are becoming less responsive to traditional advertising sites. In fact the IMC movement is also being driven by fundamental changes in the way companies market their products and services and an ongoingmarketing revolution that is changing the rules of marketing. The shifting of marketing expenditures from the traditional media advertising to other forms of promotion as well as non-traditional media ${ }^{2}$ became the reason for expanded use of below-the-line, as global communication mix, through effective brand management - Nigeria's marketplace inclusive. IMC was determined by mergers, acquisitions, affiliations outright buys among others. In fact, the role of IMC is further explained by Keller (1978) that "Building and properly managing Brand equity has become a priority for companies of all sizes, in all industry".

Within the promotional processes in the South east and the South south space are found specialists that provide collateral services located in marketing research, package design firms, printers working to reach prospective customers and provide them with effective information about a company or brands. But, creative and media provided by the IMC imperatives are almost none available. The solution to such situation is provided in the findings. Technology in its infinix flux is also conditioning tastes and consumer responses in reflective attitudinal change, particularly fashion cycle which often is an external influence. The task at the marketplace demand brand equity to the satisfaction of both client and consumer.. 


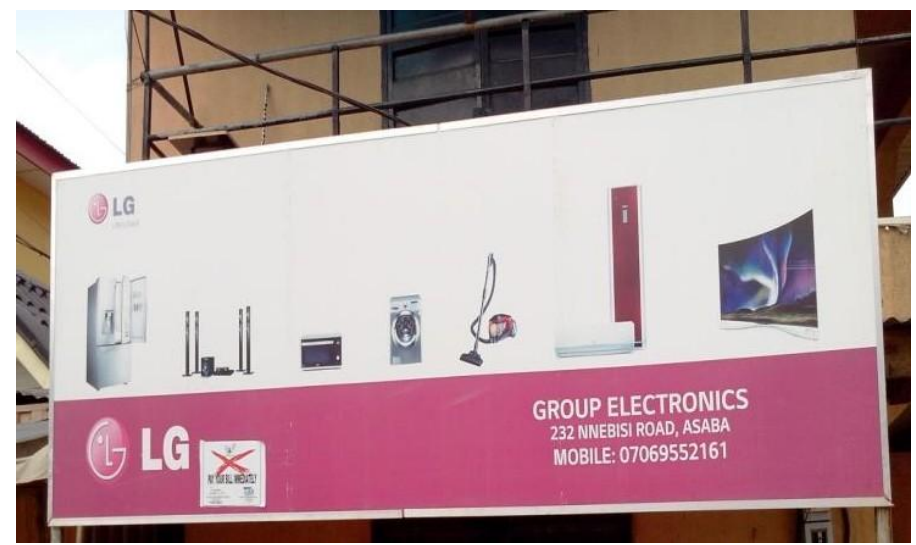

Plate 1.1:- An LG Retail signage Photo- John Amifor

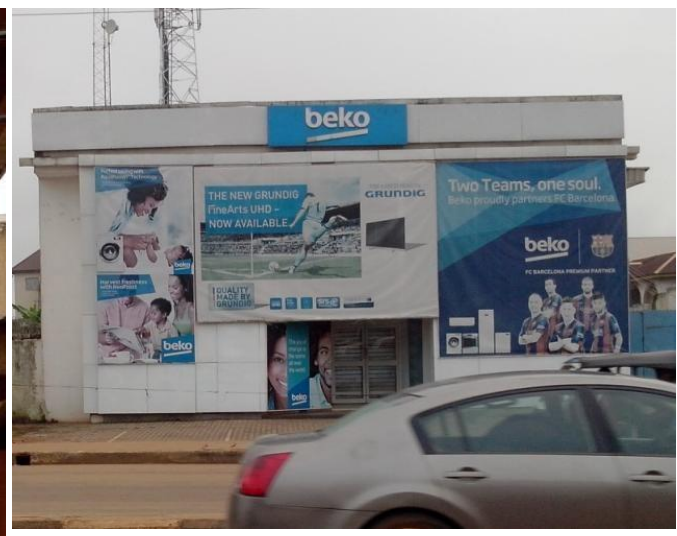

Plate 1.2:- Collateral designs on premises

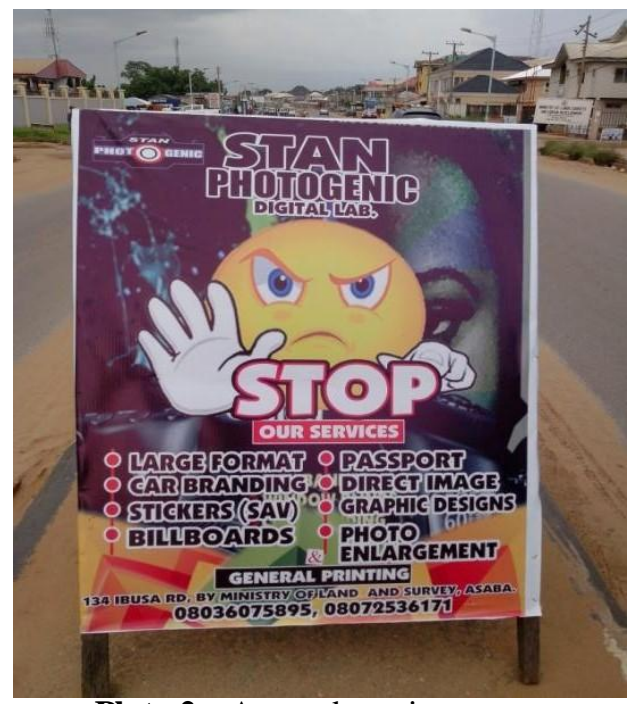

Plate 2:- An outdoor signage.

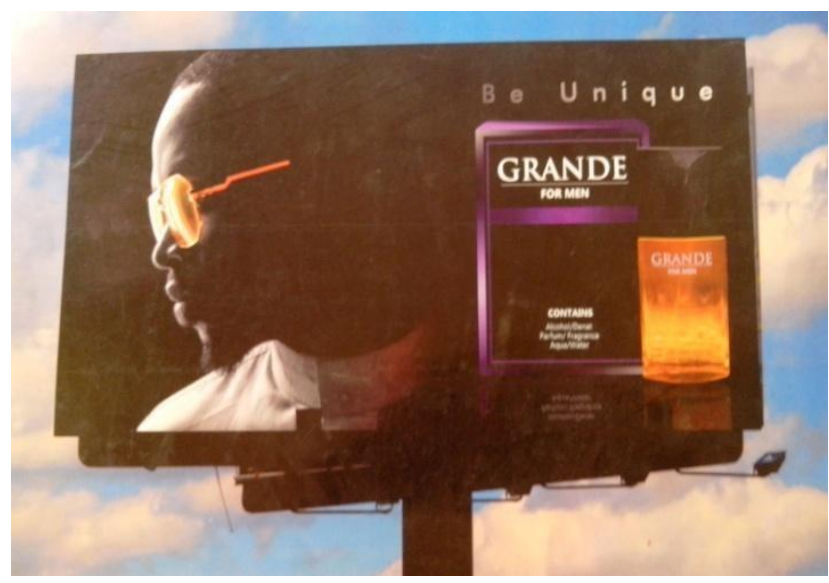

Plate 3.1:- A Billboard poster

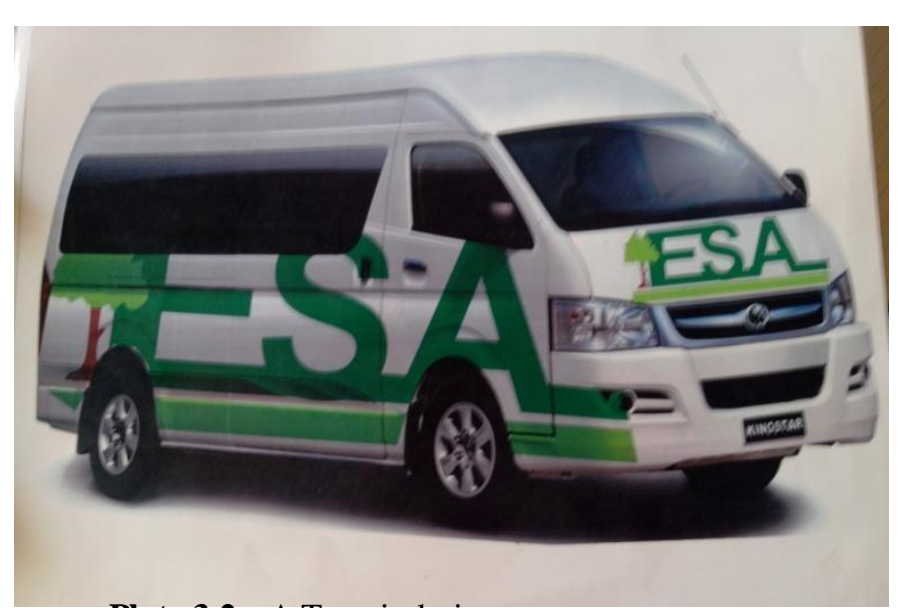

Plate 3.2:- A Transit design 


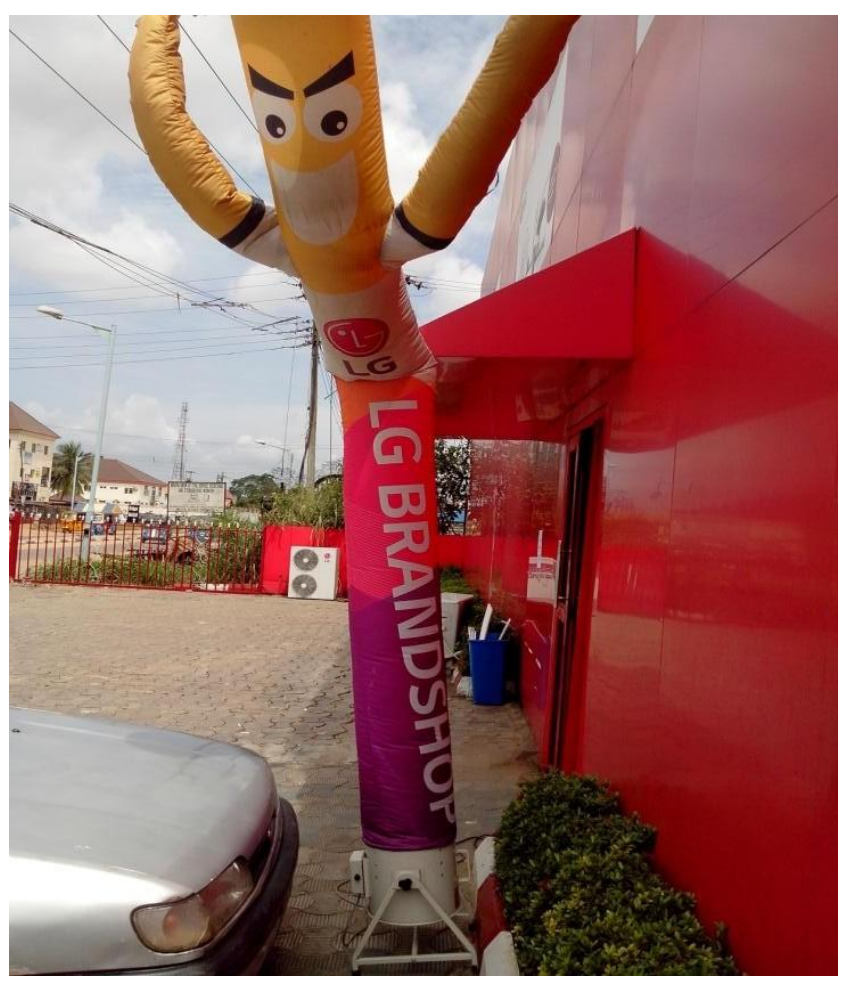

Plate 4:- Exterior LG Design. Photo-John Amifor

\section{Brand management:-}

It is important to appreciate that the brand is a fundamental means of differentiating a product from its competitors. Characteristically a brand combines name, words, symbols of design that enables consumer distinguish its source and without it no advertising takes place. Most factual is the position taken by Arens (2002) that "for consumers, brand offers instant recognition and identification. They also promise consistent, reliable standard of quality, taste, size, or even psychological satisfaction, which adds value to the product for both consumer and the manufacturer"

Implicit in Arens work is Brand Management which predicates Communication mix and necessitates at this point, an overview of wide range of bellow-the-line media or non - - measurable media that could be used in both South east and the South south market space in similar view. At the apex of it all is the communication mix that functions independent of the primary media.

\section{Marketing Plan - Strategy:-}

It is imperative that Marketing Plan must be developed from where effective advertising is focused. That leaves us practically with (1) Strategy (2) Creative idea and execution (3) media

The strategy stems from the overall marketing mix which takes into cognizance direction and focus of the advertiser.. In essence for an IMC audience most below-the-line materials have specific purposes. Even within a promotional mix target audience for sponsorships of say Ofalla Festival, Onitsha or Igue Festival, Benin demand appropriate below-the-line materials to reflect local values. The only constant is often the monopoly of sponsors brand products sold across the venue. Specific messages as public communication materials could run in the primary media (print, broadcast, or the internet) as the case may be.

Both the creative idea and creative execution equally must be tailored to reflect marketing strategy. While the media basically, rests on the segmented audience and distribution outlet. 


\section{Communication Mix:-}

With the new dispensation in IMC program, marketers continue to explore opportunities and method of reaching

prospective customers and to provide them with the desired information about products. Invariably they find the right combination of communication tools to deliver broad message effectively. Understanding of IMC tools becomes desirable.

\section{Promotional Mix:-}

The traditional domain of promotional mix is advertising, sales promotion, publicity/public relations, and personal selling in all the activities, below-the -line materials complement effort of IMC imperatives. This is achieved through the following efforts.

- Shifting of marketing expenditures to creative agencies, media and to other forms of promotions as well as non traditional media.

- A shift in market place power from manufacturers to distributors and finally retailers.

- Demand for greater accountability from advertising specialist agencies and other marketing communication firms based on good responses from the message contents.

Most important is that companies expect good returns on investment.

It was discovered that there are wide range of below-the-line and other non measurable messages that fit into specific functions while others could be used across boards. Such materials come as merchandising techniques which include display and store design in form of traditional retail outlets in the category of supermarket, departmental stores, electronic stores office equipment show rooms, cash and carry wholesalers, restaurants, fast food outlets, even beer parlor. Materials largely depend on segmented audience. For example, posters for pharmaceutical over the counter OTC outlets are simply reminder for professional in -house pharmacist on brand names and not meant for the consumers, the same goes for danglers, display stands or racks among others.

Often, depending on the interior settings posters, flyers, brochures, video display LED (light emitting diode board as well as advertisement that broadcast over in -house screens seen often in banks are also functional bellow-theline platforms. Specific tailored design including brochures, flyers could be seen at the exhibition stands for service oriented firms such as Archibuilt, caterpillar, tourism board including hospitality firms and outlets. Airline booking offices are inclusive. Aptly, the international Trade fairs organized annually at Enugu and Portharcourt require extensive below - the - line materials.

Following the information contained in the Marketing Plan target audience and nature of materials required, it is assumed that the creative people are briefed adequately.

\section{Creative Dimension:-}

The importance of creativity in below- the- line platform or any aspect of advertising is underscored by Smith and Taylor (2010,b ) as they occur: "In many consumer markets, the consumers decision to buy is often made inside, and not outside the store. In the United States, almost all of three quarters of purchase decision are made inside the store", they affirmed. In retrospect, many years ago between 1955 and 1970s when Kingsway, Stores, Leventis, UTC shopping malls existed shopping was the fashion was in vogue. Today, Cash and Carry, Shoprite are rekindling our past shopping culture. Interestingly, both (Plate 1.2), beko Collateral design and the LG kinetic branding tool as shown in (Plate 5) command attention of the pedestrians within the environment. Both designs are also environmental friendly as such effective messages

Aptly, it imperative to re- engage the global culture and society; also, to re- engage the possibilities the global culture presents particularly, the global manufacturers competitive drive in these market zones, if the local manufacturers aim to reach the next level: the West African market and beyond.

\section{Media:-}

Often in merchandise shops, proliferation and cacophony of brands colorfully designed products as well as Displayed materials present problem for retailers. Also, over the years, trends towards self-service retailing increased the importance of point of sales materials. The reason resonates from created situation where fewer knowledgeable hands are the sales people, therefore customer resort to individual sales purchase decisions. Effective design is the solution as purchasers make instant purchase decisions. Such situation demand that even for 
client's package design, packages must be effective as silent advertisers in their body content. Space within the environment is also premium to accommodate Point of sales array of materials listed below. Most of these media channels are desired in the markets under study.

(1) Flyers

(2) Package designs (silent advertiser); (3) Stickers;

(4) Posters;

(5) Show cards and danglers;

(6) Branded racks or display units; (7) Dump bins;

(8) Souvenirs (Calendar, face caps, tee-shirts, bandanas all promotional items) (9) Three dimensional:

- Holograms

- $\quad$ Free standing floor displays; (10) Electronic gadgets;

- $\quad$ Spotlight systems

- Video walls;

- Plasma screens;

- Illuminated display systems with fiber optics

- $\quad$ Magic mirrors

- Interactive system e.g. product advice systems, personal consultation systems, smartcards, POS suggested items.

(11) In-store sampling; (12) Window display;

(13) Digital imaging and web based merchandising analysis tools.

Culled from Smith and Taylors,2010.

\section{Creative specialists:-}

Good creative strategy and execution determines the effectiveness of success of below the line materials visibility

In identified functions either for sales promotion, event marketing, public relations, direct selling or word of mouth, even sponsorship of festivals as peculiar with Nigeria. Each design is tailored and predicated by knowledge based on research concerning the target audience and subsequently environmental realities such as cultural idiosyncrasy.

Usually the creative direction is a bye product adapted from the main design originated for the primary media. It could be deviated by generating fresh, unique and appropriate or relevant ideas, particularly if the advertiser lacks the capacity to engage a full service agency for campaign.

Given the complexities, competition and cacophony of designs at the marketplace, materials for branding demand good design literacy at the cognitive level. Specialized creative advertising agencies that provide only creative services are the solution to the absence of full scale agencies. They always have among them copy writers and designers they; they do not have media, research and media planning propensity like the full service agencies.

However, they maintain expertise in desired creative proficiency while the client controls its marketing communication network through internal network. Good knowledge of the audience, the extent of the market, cost, functionality, tastes, emerging fashion cycles, habits and idiosyncrasies of global consumers are useful components of design considerations.

Attitude is above all the contexts considered necessary for bellow-the-line effective branding. This emanates from research and adaptations using principles of design effectively. Creative specialists are almost not available in these geographical regions. But, they can be located. After all, the essence of branding is to make the difference and that underscores the ability of the designer to go beyond the boundaries.

\section{Challenges and Solutions:-}

There are a lot of impresarios in the market zone with financial muzzles and they are largely untrained; they own the

Collateral production plants such as Stan Photogenic (Plate2). Their services are cheap, therefore competitive comparatively with effective design concept. 
The cost of producing effective design attracts good remuneration owing to time spent on concept development suitable for desired brand visibility. Comparatively, (Plates1.1 and 1.2) as foreign sourced designs suggest visible divide and creative differences with (Plate2)," Stan Photogenic "which is a local signage with cacophony of content that lacks readability from the road users. In addition, in (Plates 1.1, and 1.2) could be observed a minimalist use of dynamic space as design principle to suggest dexterity, appreciation of the target audience in transit and the need to be effective. They are both distributor's signage, and products of standardized design from the client's head office. Often their creative files are sent to the local affiliate to add individual distributor's particulars for local production.

Following the survey result conducted, (2) out of 4 designs acknowledged by 35 respondents representing $87.5 \%$ of the identified external designs were products of Nnamdi Azikiwe University visual communication design graduates. This was revealed to the participants by the facilitator of the seminar who incidentally was the author of this paper as well as the mentor of these local designers. Dexterity added to minimalist approach to designing are within reach among graduates of Nnamdi Azikiwe University visual communication products. Their training in copy writing, motion graphics, photography video and television, advertising and promotion as well as animation makes them capable of producing global content designs. The reason is not far-fetched, mentoring is industry compliant. The messages of (Plates3.1 and 3.2) respectively border on semiotics: that is language and sciences of signs which brings to fore meanings associated with the messages; both in form and content as Global Habitat campaign is graphically embodied in the designs, even in (Plate4) also. The Module required for a Creative Agency or Boutique is highly recommended for effective visibility of Bellow- the- line message delivery.

\section{Architectural Module:-}

Full service agency is best suited to achieve the difference because of conglomeration of team work under one roof.

Alternatively, creative studio or boutique is highly recommended to attain designs that set the limit at the boundary. The architecture to include:

\section{Chief Executive Officer:-}

A senior partner must be in charge of daily routine and operations. The portfolio manages the client's budget and work schedule and maintains competitiveness in industry. Additionally, the portfolio include concept

Development and quality control.

\section{Creative Director:-}

The portfolio anchors creative ideas to push boundaries in Print, Electronics and Web message construct. This is in addition to copy writing as well as production as an inclusive function.

\section{Motion Design Director:-}

The portfolio requires a creative hand knowledgeable in 2D and 3D interface, animation, motion graphics, art and design, copy writing and production.

\section{Finance and Facilities:-}

Finance could be sourced from family, friends and banks, including the Federal government agencies such as Bank of Industry. Modest facilities required include: Nikon D5000, 5100, or 7000, they are dual function super cameras for both still and video. Laptops, Tripods, Umbrella and lighting, software s, furniture, and rent. Total minimum take off estimate is 10Million Naira.

\section{Conclusion:-}

As the global market diversified since 1980s Integrated Marketing Communication imperatives and Technological Spin offs continue to condition creative possibilities in advertising, below - the -line media inclusive. IMC global dictates demand marketing mix, communication mix as well as the media mix to locate target audience in the South East and South-South market zones. The markets present lopsided competitive edge in favour of the multinational concerns against the local entrepreneurs with limited budget. Recourse to well manage below - the - line brand visibility with limited budget dexterity and creative skills at plotting effective design possibilities within limited budgets has become imperative. Added to effective design are located tools such as maximizing customer care, creating platform to deal with customer complains, enquiries, feedback, interactive website and hotline as prerequisite for building brand equity between the client and the customer. 
With the absence of full service agency in the zone, creative shop is the optimum option. Good industry compliant creative professionals have been traced to the local institution, Nnamdi Azikiwe University as evidenced in this paper content. Funding could be sourced from several federal government intervention sources such as the Small and Medium Enterprises (SME) intervention scheme.

\section{Reference:-}

1. Arens, W. (2002) Contemporary Advertising New York: MC Graw- Hill/Irwin.

2. Belch, G and Belch, M (2012) Advertising and Promotion, An Integrated Marketing Communication Perspective New York: McGraw- Hill/ Irwin.

3. Burton, G. (2010) Media and Society Critical Perspective New York: Open University Press.

4. Iwuala, N. O.(2011) Africa Report Special Issue Nigeria. No. 35.

5. Keller, K (1978) "The Brand Report Card” Harvard Business Review, 78 (1) (January/February.

6. Moriarty, S. Mitchell, N. and Wells, W. (2009) Advertising Principles Practice Upper Saddle River: Pearson

7. Prentice Hill.

8. Rubin, R. Rubin,A.Haridakis, P. and Piele, L. (2010) Communication Research Strategies and Sources. $\left(7^{\text {th }}\right.$. Ed) Boston: Wadsworth Centage.

9. Shultz, G. (in Belch and Belch, 2012,a)

10. Smith, P.R and Taylor, J (2010) Marketing Communications, An Integrated Approach London: Centage Press.

11. Vakratsas, D and Ambler, T. (in Belch and Belch,2012, b). 